\title{
Article
}

\section{Establishment of Silane/GO Multistage Hybrid Interface Layer to Improve Interfacial and Mechanical Properties of Carbon Fiber Reinforced Poly (phthalazinone ether ketone) Thermoplastic Composites}

Shan Cheng 1,2,3, Nan Li 1,3,4,*, Yuxi Pan 1,3, Bing Wang 1,2,3, Haoyue Hao 1,2,3, Fangyuan Hu 1,2,3, Cheng Liu 1,3 ${ }^{1}$, Yousi Chen ${ }^{1,3}$ and Xigao Jian ${ }^{1,2,3, *}$

1 State Key Laboratory of Fine Chemicals, Department of Polymer Science and Materials, School of Chemical Engineering, Dalian University of Technology, Dalian 116024, China; 15610331427m@sina.cn (S.C.); pan.yuxi@163.com (Y.P.); $17864301035 @ 163 . c o m$ (B.W.); Haohaoyue@mail.dlut.edu.cn (H.H.); hufangyuan@dlut.edu.cn (F.H.); liuch1115@dlut.edu.cn (C.L.); chenyousi@dlut.edu.cn (Y.C.)

2 School of Materials Science and Engineering, Dalian University of Technology, Dalian 116024, China

3 Liaoning Province Engineering Centre of High-Performance Resins, Dalian University of Technology, Dalian 116024, China

4 State Key Laboratory for Modification of Chemical Fibers and Polymer Materials, Donghua University, Shanghai 201620, China

* Correspondence: polymerlinan@dlut.edu.cn (N.L.); jian4616@dlut.edu.cn (X.J.)

check for updates

Citation: Cheng, S.; Li, N.; Pan, Y.; Wang, B.; Hao, H.; Hu, F.; Liu, C.; Chen, Y.; Jian, X. Establishment of Silane/GO Multistage Hybrid Interface Layer to Improve Interfacial and Mechanical Properties of Carbon Fiber Reinforced Poly (phthalazinone ether ketone) Thermoplastic Composites. Materials 2022, 15, 206. https://doi.org/10.3390/ma15010206

Academic Editor:

Joanna Ryszkowska

Received: 28 September 2021

Accepted: 6 December 2021

Published: 28 December 2021

Publisher's Note: MDPI stays neutral with regard to jurisdictional claims in published maps and institutional affiliations.

Copyright: (C) 2021 by the authors. Licensee MDPI, Basel, Switzerland. This article is an open access article distributed under the terms and conditions of the Creative Commons Attribution (CC BY) license (https:// creativecommons.org/licenses/by/ $4.0 /)$.

\begin{abstract}
This study focused on the faint interface bonding between carbon fiber (CF) and poly(phthalazinone ether ketone) (PPEK) thermoplastic, a multistage hybrid interface layer was constructed via the condensation reaction of N-[3-(Trimethoxysilyl)propyl]-N,N,N-trimethylammonium chloride $\left(\mathrm{KHN}^{+}\right)$and the electrostatic adsorption of graphene oxide (GO). The influence of the contents of GO $(0.2 w t \%, 0.4 w t \%, 0.6 w t \%)$ on the interfacial properties of composites was explored. FTIR, Raman spectra, XPS tests indicated the successful preparation of CF-KHN ${ }^{+}-\mathrm{GO}$ reinforcements. The multistage hybrid interface layer significantly increased fiber surface roughness without surface microstructure destruction. Simultaneously, polarity and wettability are remarkably improved as evidenced by the dynamic contact angle experiment. The interlaminar shear strength (ILSS) and flexural strength of the CF/PPEK composites with $0.4 \mathrm{wt} \% \mathrm{GO}\left(\mathrm{CF}-\mathrm{KHN}^{+}-4 \mathrm{GO}\right)$ were 74.57 and $1508 \mathrm{MPa}$, which was $25.2 \%$ and $23.5 \%$ higher than that of untreated CF/PPEK composite, respectively. Dynamic mechanical analysis proved that $\mathrm{CF} / \mathrm{GO} / \mathrm{PPEK}$ composites have excellent high-temperature mechanical properties. This study furnishes an unsophisticated and valid strategy to build an interface transition layer with a strong binding force, which would offer a new train of thought in preparing high-performing structural composites.
\end{abstract}

Keywords: carbon fiber; thermoplastic composites; interface/interphase; graphene; silane

\section{Introduction}

Continuous carbon fiber (CF) reinforced polymer composites has been far and wide used as high-performance structural materials in the aerospace industry, nuclear industries, automobiles, machinery, and chemical industries for possessing a combination of commendable properties, such as low density, high strength, strong impact toughness, fatigue endurance [1-5]. In particular, continuous carbon fiber reinforced thermoplastic (CFRTP) composites have many unique advantages, such as high toughness, fatigue resistance, rapid production, melting welding, green recycling, long-term storage of raw materials. In recent years, CFRTP has been applied to large components such as aircraft skin, fairing, wings, and vertical tail, and developed rapidly [6].

It is well-known that the interface of the composite is the bridge between fibers and matrix, which affects the load transfer and crack initiation and propagation [7]. Excellent 
interface properties can be reduced stress concentration and improve mechanical properties and thermal resistance for the composites [8]. Two main reasons lead to the poor interface bonding of CFRTP. On the one hand, the skin layer in the two-dimensional "skin-core" structure in carbon fiber composed of regular graphite structure possesses a smooth surface and low chemical activity. On the other hand, thermoplastic is highly chemically inert, and no chemical reaction occurs during the hardening process. Therefore, considerable studies have been concentrating on the surface treatments of $\mathrm{CF}$ to heighten the interfacial bonding of CFRTPs [9-11]. Plasma treatment [12], high-energy irradiation [13], sizing coatings [14,15], chemical grafting [16] techniques, etc., bring forth ways and means to settle the weak interface adhesion of CFRTP sectors.

Graphene oxide (GO), a single layer of graphite oxide bearing oxygen functional groups on its basal side and boundary zone, has already attracted tremendous interest in the domain of polymer composite science on account of its plentiful oxygen-containing functional groups $[17,18]$. Compared to other carbon fillers, such as carbon nanofibers and carbon nanotubes, its high special surface area, excellent wettability, low cost, large-scale preparation, and remarkable mechanical properties make GO the optimal material for next-generation hierarchical reinforcements of polymer composites $[10,19,20]$. Recently, some studies have been devoted to chemically grafting GO onto the CF surface to realize the interface enhancement. Huang et al. [21] reported the controllable particle size graphene oxide (GO) sheets were grafted on the CF applying poly(oxypropylene) diamines (D400) as the bridging agent, which led to interlaminar shear strength improving by $34 \%$. Liu et al. [22] grafted GO onto CF by covalent bond composited with PEEK, which led to flexural strength increasing from $762 \mathrm{MPa}$ to $981 \mathrm{MPa}$. However, it is difficult to evenly graft GO onto CF surface because of the reactivity and steric hindrance, which is easy to form stress concentration at the interface phase [23]. Physical surface coating could achieve the goal of uniform distribution of graphene carbon fiber surface. GO attach to CF based on physical interactions and Van der Waals forces, which are propitious to nanoplatelets peeling from CF surface, followed by interface delamination. To sum up, the uniform distribution of GO nanosheets on the CF surface through strong binding force is the key to maximize the interface enhancement efficiency of GO. The physical surface coating has no negative effects on the structure and performance of carbon fiber. Nevertheless, aside from sizing, physical surface coating is hardly investigated in the literature. The thermosetting sizing agents are the most commonly used sizing agents, however, with poor compatibility with thermoplastic matrix [24-26]. This incompatibility leads to poor mechanical strength of CFRTP, especially in terms of interlaminar shear strength (ILSS). Sizing agent doped nanoparticles can improves the compatibility between sizing agents and thermoplastic matrix, but also cause agglomeration $[14,27,28]$.

Poly(phthalazinone ether ketone) (PPEK), as a promising thermoplastic matrix, possesses excellent heat-resistant, prominent mechanical property and unique solubility owing to its twisted and noncoplanar macromolecular chain structures. Its glass transition temperature $\left(T_{g}\right)$ can reach up to $263{ }^{\circ} \mathrm{C}$, which is much higher than poly (ether ketone) (PEEK, $T_{g}=143{ }^{\circ} \mathrm{C}$ ), poly (phenylene sulfide) (PPS, $T_{g}=85^{\circ} \mathrm{C}$ ) and polysulfone (PSU, $\left.T_{g}=185^{\circ} \mathrm{C}\right)[16,29]$ and other traditional high-performance thermoplastic. In addition, PPEK can be dissolved in organic solvents such as chloroform, 1-Methyl-2-pyrrolidinone (NMP), dimethylacetamide (DMAc) under room temperature, which overcomes the insoluble shortcomings of traditional thermoplastic resins and realizes the preparation of prepregs by solution impregnation. Nevertheless, PEEK and PPS can only dissolve in concentrated sulfuric acid, and their composites can only be fabricated by melt impregnation. The method usually involves high cost and energy consumption [24].

Given the above, in order to improve the interface performance of CF/PPEK composite, GO/CF multi-scale reinforcement was prepared by electrostatic interaction. First, the abundant hydroxyl groups on the carbon fiber surface reacted with the positively charged silane coupling agent, $\mathrm{N}$-trimethoxysilylpropyl-N,N,N-trimethylammonium chloride $\left(\mathrm{KHN}^{+}\right)$, to form a positively charged silane coating on CF surface. Noteworthily, 
silane layer with plentiful hydroxyl groups is easily prepared via the gradual hydrolysis and condensation of multifunctional silicon sources such as tetraethoxysilane and silane coupling agents. In our previous study, the silane layer contained POSS is beneficial to the interface performance and hygrothermal aging resistance of CFRTP [2,30]. Second, GO bearing a large number of carboxyl groups can be ionized in water. The positively charged $\mathrm{CF}$ coated by silane is put into an aqueous dispersion of $\mathrm{GO}$, and then the $\mathrm{GO}$ nanosheets could be adsorbed on CF surface by electrostatic action. The electrostatic force between CF and GO is far stronger than Van der Waals forces. Furthermore, the GO nanosheets can be evenly distributed onto the CF surface because of the equal distribution of positive charge in the silane coating. The force of electrostatic adsorption is much greater than other physical adsorption methods [31] and the electrostatic adsorption method is a non-destructive method that there is no need to process the fiber by ionization, acidification, etc. [32,33]. The investigation showed a very remarkable improvement of interfacial interlocking proved by the mechanical properties and the morphology of fractured surfaces, and the interlaminar shear strength.

\section{Experiment}

\subsection{Materials}

PPEK resin, the molecular structure is shown in Figure 1, were purchased from Dalian Polymer New Material Co., Ltd., Liaoning, China with intrinsic viscosity [ $\eta]$ of $0.80 \mathrm{dL} / \mathrm{g}$. The commercially available continuous carbon fiber used in this study was T700 (12 K) with an average diameter of $7 \mu \mathrm{m}$, obtained from Toray Industries, Inc. Graphene Oxide gel and $\mathrm{N}$-[3-(Trimethoxysilyl)propyl]-N,N,N-trimethylammonium chloride were purchased from Aladdin Bio-Chem Technology Co., Ltd. (Shanghai, China). All solvents and other reagents were provided by commercial sources and used as received.

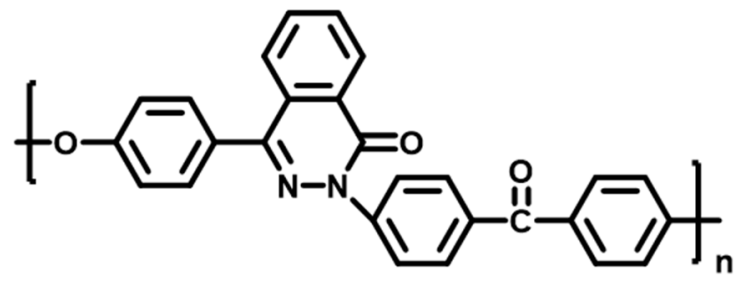

Figure 1. Molecular structure of PPEK.

\subsection{Preparation of $\mathrm{KHN}^{+}$Silane Functionalized $\mathrm{CF}$}

The CF bundles were refluxed with ethyl alcohol and acetone for $48 \mathrm{~h}$ and then dried in a vacuum oven at $80^{\circ} \mathrm{C}$ to eliminate the interference factor of commercial size and remove dust, grease, named Untreated CF. Then, $4 \mathrm{~mL}$ of N-[3-(Trimethoxysilyl)propyl]$\mathrm{N}, \mathrm{N}, \mathrm{N}$-trimethylammonium chloride $\left(\mathrm{KHN}^{+}\right)$were dissolved into $50 \mathrm{~mL}$ methanol. Then, $5 \mathrm{~g} \mathrm{CF}$ wrapped around a glass frame were added into the above solution and stirred at $60{ }^{\circ} \mathrm{C}$ for $6 \mathrm{~h}$. Subsequently, the modified CF were washed repeatedly with ethanol, dried in an oven at $80^{\circ} \mathrm{C}$ for $4 \mathrm{~h}$, which was denoted as CF-KHN ${ }^{+}$(Figure 2).

\subsection{Preparation GO/CF Muti-Scale Reinforcements}

A quantitative amount of GO was added to deionized water, sonicated for $1 \mathrm{~h}$ (Granbo Technology Industrial Shenzhen Co., Ltd., $450 \mathrm{~W}, 40 \mathrm{kHz}$ ), and configured into a graphene oxide aqueous suspension with content of $0.2 \mathrm{wt} \%, 0.4 \mathrm{wt} \%$, and $0.6 \mathrm{wt} \%$, respectively. Then, the CF was immersed in the suspension, and stand for $24 \mathrm{~h}$. Finally, the obtained CF were dried in an oven at $80^{\circ} \mathrm{C}$ for $4 \mathrm{~h}$, and denoted as $\mathrm{CF}-\mathrm{KHN}{ }^{+}-2 \mathrm{GO}, \mathrm{CF}-\mathrm{KHN}{ }^{+}-4 \mathrm{GO}$, and $\mathrm{CF}-\mathrm{KHN}^{+}-6 \mathrm{GO}$. 

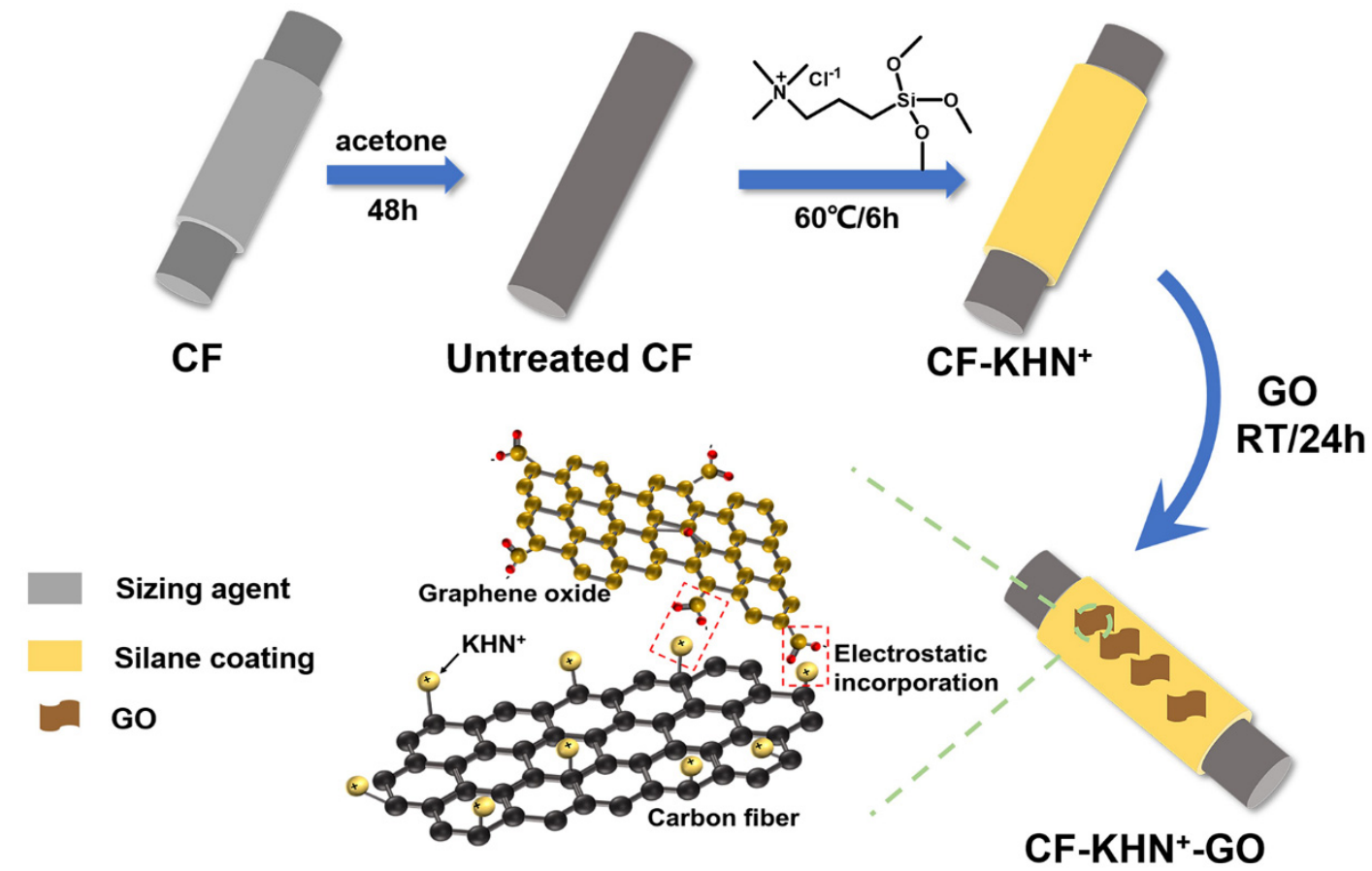

Figure 2. The schematic diagram of fabrication GO/CF multi-scale reinforcement.

\subsection{Preparation of CF/PPEK Composites}

CF/PPEK composites were prepared through the parallel solution impregnation process [2]. First, the CF was wound on a $250 \mathrm{~mm} \times 150 \mathrm{~mm}$ iron frame, and $13 \mathrm{~g}$ PPEK resin were dissolved in $100 \mathrm{~mL}$ of NMP (13 wt\%). Then, the CF-wrapped iron frame was immersed in the PPEK/NMP resin solution. After being fully soaked, the iron frame wrapped with CF was placed in a blast oven for drying. The drying system was $100{ }^{\circ} \mathrm{C} / 2 \mathrm{~h}$, $120{ }^{\circ} \mathrm{C} / 2 \mathrm{~h}, 150{ }^{\circ} \mathrm{C} / 2 \mathrm{~h}, 180{ }^{\circ} \mathrm{C} / 2 \mathrm{~h}, 280{ }^{\circ} \mathrm{C} / 2 \mathrm{~h}$. Finally, the $\mathrm{CF}$ reinforced PPEK resin unidirectional tape was cut into $100 \mathrm{~mm} \times 60 \mathrm{~mm}$ prepregs. Fourteen piles of neatly tailored prepreg plies were stacked unidirectionally into a steel mold with the pressure of $5 \mathrm{MPa}$ at $350{ }^{\circ} \mathrm{C}$ for $2 \mathrm{~h}$.

\subsection{Characterization Methods}

Thermogravimetric analyses (TGA) of the polymers were performed on a Mettler TGA/SDTA851 thermogravimetric analysis instrument heating from $30{ }^{\circ} \mathrm{C}$ to $800{ }^{\circ} \mathrm{C}$ under nitrogen atmosphere at a heating rate of $20^{\circ} \mathrm{C} / \mathrm{min}$. The differential scanning calorimetric (DSC) was measured on Mettler DSC822 under a nitrogen flow (50 mL/min) heating rate of $20{ }^{\circ} \mathrm{C} / \mathrm{min}$ from 30 to $350{ }^{\circ} \mathrm{C}$. The TGA and DSC curves of PPEK and CF/PPEK composites were presented in Figure S3.

FTIR spectrophotometer was performed with ThermoFisher, 6700 (USA), which was applied to characterize the chemical structure of different CF. The specimens were prepared with powder-pressed $\mathrm{KBr}$ pellets. FTIR tests were carried out scanning the specimens 64 times in the wavenumber range of $400-4000 \mathrm{~cm}^{-1}$ with the resolution of $16 \mathrm{~cm}^{-1}$.

XPS was used to detect surface composition and analyze the functionalization reaction mechanisms. The spectra were collected using a Thermo Fisher Scientific (ESCALAB250Xi, UK) with a monochromatic Al Ka source $(1486.6 \mathrm{eV})$ at base pressure of $2 \times 10^{-9}$ mbar.

Raman spectroscopy from 500 to $4000 \mathrm{~cm}^{-1}$ was used an $\mathrm{Ar}^{+}$laser (wavelength is $514.5 \mathrm{~nm}$ ) at room temperature by Invia Renishaw 2000 spectrometer. Raman focusing and imaging was conducted using a confocal microscope with an objective of $50 \times$ and the spot diameter of $1-2 \mu \mathrm{m}$.

The surface morphology of CF according to different modifications and general analyses for the material after mechanical tests of CF/GO/PPEK composites were observed 
by SEM (Japan Hitachi Nake high-tech enterprise, SU8220). All the samples were coated with a thin conductive gold layer before SEM measurements. The surface roughness of different reinforcements was determined by a dimension icon atomic force microscope (AFM) (Bruker, Dimension Icon)

A dynamic contact angle metre and tensiometer (DCAT21, Data Physics Instruments, Germany) were used to characterize the dynamic contact angle and surface energy. Deionized water $\left(\gamma^{d}=21.8 \mathrm{mN} / \mathrm{m}, \gamma=72.8 \mathrm{mN} / \mathrm{m}^{-1}\right)$ and diiodomethane $\left(\gamma^{d}=50.8 \mathrm{mN} / \mathrm{m}\right.$, $\gamma=50.8 \mathrm{mN} / \mathrm{m}, 99 \%$ purity, Alfa Aesar, Ward Hill, NY, USA) were applied as the test liquids. The dispersive and polar components of the hybrid CF were calculated according to Equations (1) and (2) [34,35]:

$$
\begin{gathered}
\gamma_{1}(1=\cos \theta)=2\left(\gamma_{1}^{p} \gamma_{f}^{p}\right)^{\frac{1}{2}}+2\left(\gamma_{1}^{d} \gamma_{f}^{d}\right)^{\frac{1}{2}} \\
\gamma_{f}=\gamma_{f}^{p}+\gamma_{f}^{d}
\end{gathered}
$$

where $\gamma_{1}, \gamma_{1}^{d}$ and $\gamma_{1}^{p}$ are the surface tension of the test liquid, its dispersive and polar component, respectively.

The interlaminar shear strength (ILSS) (see Figure S1 for schematic diagram) of the CF/PPEK composites were performed on Instron 5982 Universal test machine (Boston, MA, USA). The specimen dimensions were $20 \mathrm{~mm} \times 10 \mathrm{~mm} \times 2 \mathrm{~mm}$ and the specimens were measured at the cross-head speed of $1 \mathrm{~mm} / \mathrm{min}$, according to the ISO 14130 standard. At least 5 samples were tested for each processing condition. The ILSS values were calculated according to Equation (3):

$$
I L S S=\frac{3 P_{b}}{4 b h}
$$

where $P_{b}$ is the maximum compression load at fracture $(\mathrm{N}), b$ is the width of the specimen $(\mathrm{mm})$, and $h$ is the thickness of the specimen (mm).

The flexural strength of the CF/PPEK composites (see Figure S2 for schematic diagram) was tested according to ASTM D790-10 using a three-point flexural test method. The size of the specimen was $80 \mathrm{~mm} \times 12.5 \mathrm{~mm} \times 2 \mathrm{~mm}$, and they were tested at the crosshead movement rate of $2 \mathrm{~mm} / \mathrm{min}$, with the span of $64 \mathrm{~mm}$. At least five measurements were performed for each composite and get the average values of flexural strength and modulus.

Dynamic mechanical analysis (DMA) tests can obtain the dynamic mechanical spectra (tan $\delta$, storage modulus, loss modulus). DMA were carried out with a TA Q800 instrument at $1 \mathrm{~Hz}$ and the heating rate of $3{ }^{\circ} \mathrm{C} / \mathrm{min}$ under a single cantilever mode to characterize $T_{g}$. The test temperature ranged from $25^{\circ} \mathrm{C}$ to $300^{\circ} \mathrm{C}$. The composite sample dimensions were $35 \mathrm{~mm} \times 6 \mathrm{~mm} \times 2 \mathrm{~mm}$ for the composite samples. In DMA, a complex modulus $\left(G^{*}\right)$, an elastic modulus $\left(G^{\prime}\right)$, and an imaginary (loss) modulus $\left(G^{\prime \prime}\right)$ are calculated from the material response to the sine wave. These different moduli allow better characterization of the material, because we can now examine the ability of the material to return or store energy $\left(G^{\prime}\right)$, to its ability to lose energy $\left(G^{\prime \prime}\right)$, and the ratio of these effects (tan delta), which is called damping.

$$
\begin{aligned}
& G^{*}=G^{\prime}+i G^{\prime \prime} \\
& \tan \delta=G^{\prime \prime} / G^{\prime}
\end{aligned}
$$

\section{Results and Discussion}

\subsection{Surface Structures and Chemical Elements of CF}

The FTIR spectra of GO, untreated CF, CF-KHN ${ }^{+}$, and CF-KHN ${ }^{+}-4 \mathrm{GO}$ were shown in Figure 3. The absorption peak of GO chiefly consists of stretching vibrations of $\mathrm{O}-\mathrm{H}$ from the hydroxyl and carboxyl groups at $3400 \mathrm{~cm}^{-1}$. The stretching bands at $1729 \mathrm{~cm}^{-1}$ locate $\mathrm{C}=\mathrm{O}$ from carboxyl. This indicates that a large number of oxygen-containing functional groups exist on the GO surface. The absorption peak in the range of $3250 \sim 3450 \mathrm{~cm}^{-1}$ corresponds to the $-\mathrm{OH}$ stretching vibration peak of the CF surface. The characteristic 
bands at $952 \mathrm{~cm}^{-1}$ and $1141 \mathrm{~cm}^{-1}$ in CF-KHN ${ }^{+}$spectrum are ascribed to the stretching vibration of Si-O-Si and $\mathrm{Si}-\mathrm{OH}$, indicating the existence of silane coating on the $\mathrm{CF}-\mathrm{KHN}^{+}$ surface. After introducing GO, the symmetric stretching of the carboxylate group appeared at $1420 \mathrm{~cm}^{-1}$, which can be attributable to the abundant carboxyl groups on the graphene oxide. It shows that graphene oxide has been introduced to the surface of the fiber.

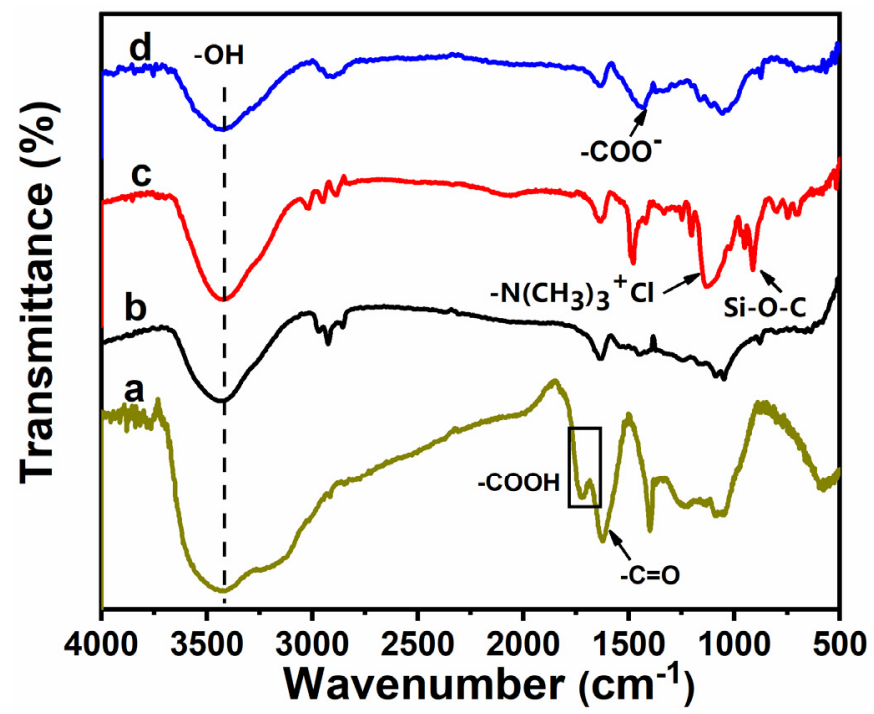

Figure 3. FTIR spectra of carbon fiber: (a) GO, (b) Untreated CF, (c) $\mathrm{CF}_{-} \mathrm{KHN}^{+}$, (d) CF-KHN ${ }^{+}-4 \mathrm{GO}$.

Figure 4 shows Raman spectra of three kinds of CF surface. The Raman spectrum of $\mathrm{CF}$ has two distinct characteristic peaks, which are the D-band absorption peak at about $1360 \mathrm{~cm}^{-1}$ and the G-band absorption peak at $1600 \mathrm{~cm}^{-1}$. Peak D represents the defect amorphous carbon structure on the surface of the $\mathrm{CF}$, corresponding to $\mathrm{sp}^{3}$ hybridized carbon atoms; Peak $\mathrm{G}$ represents the regular and ordered graphitized carbon structure on the surface of the $\mathrm{CF}$, corresponding to $\mathrm{sp}^{2}$ hybridized carbon atoms [36]. The integrated intensity ratio $(\mathrm{AD} / \mathrm{AG})$ is an important indication of the degree of graphitization of the $\mathrm{CF}$ surface. The larger value of $\mathrm{AD} / \mathrm{AG}$, the higher the degree of disorder on the $\mathrm{CF}$ surface [37]. Perform peak fitting of Raman spectrum, and new peaks $\mathrm{T}$ and $\mathrm{A}$ appear at 1160 and $1510 \mathrm{~cm}^{-1}$, respectively [38]. The values of AD/AG are shown in Table 1.
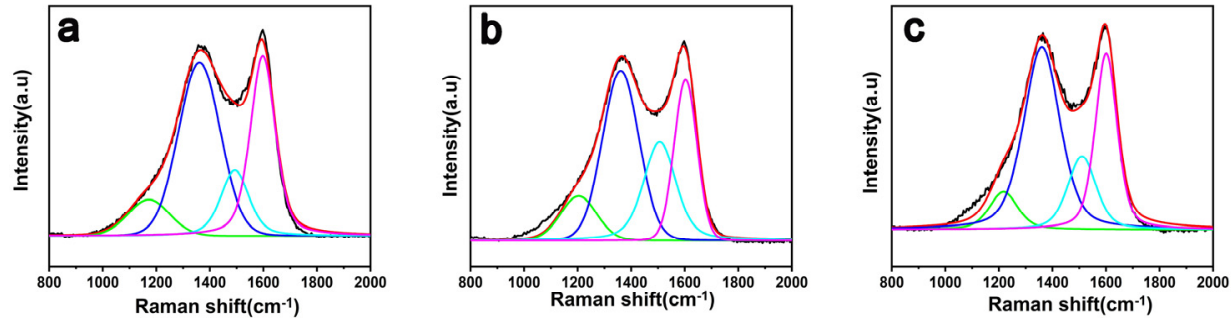

Figure 4. Raman spectra of carbon fiber (a) Untreated CF, (b) $\mathrm{CF}-\mathrm{KHN}^{+}$, (c) $\mathrm{CF}-\mathrm{KHN}^{+}-4 \mathrm{GO}$.

Table 1. Wavenumbers of $\mathrm{D}, \mathrm{G}$ and $\mathrm{A}$ bands and the calculated values of "AD/AG" acquired from carbon fibers.

\begin{tabular}{|c|c|c|c|c|}
\hline & D & G & $\mathbf{A}$ & \\
\hline Samples & $W\left(\mathrm{~cm}^{-1}\right)$ & $W\left(\mathrm{~cm}^{-1}\right)$ & $W\left(\mathrm{~cm}^{-1}\right)$ & $\mathrm{R}=\mathrm{AD} / \mathrm{AG}$ \\
\hline Untreated CF & 1359 & 1596 & 1512 & 2.29 \\
\hline CF-KNH ${ }^{+}$ & 1363 & 1601 & 1525 & 2.70 \\
\hline $\mathrm{CF} \mathrm{KNH}^{+}-4 \mathrm{GO}$ & 1364 & 1602 & 1529 & 3.38 \\
\hline
\end{tabular}


The Raman parameters of the modified CF have undergone certain changes. The Raman peaks of the D peak and the $G$ peak are slightly blue-shifted, and the integrated intensity ratio $\mathrm{AD} / \mathrm{AG}$ rises from 2.29 (Untreated $\mathrm{CF}$ ) to $2.70\left(\mathrm{CF}-\mathrm{KNH}^{+}\right)$. It indicated that the number of $\mathrm{sp}^{3}$ hybrid carbon atoms on the $\mathrm{CF}-\mathrm{KNH}^{+}$surface increases with the modification reaction and the disorder of the $\mathrm{CF}-\mathrm{KNH}^{+}$surface has the same trade. Meanwhile, the result further proves that the CF surface have been introduced with a silane coating. With the GO contained negative charge adding, the AG/AD increases to 3.38, the degree of disorder on the $\mathrm{CF}-\mathrm{KNH}^{+}-4 \mathrm{GO}$ surface is further improved, and the reaction activity is further increased.

XPS was used to analyze the changes of surface element content and chemical composition before and after CF modification. Figure 5a shows the XPS wide-scan spectra of various CF. Untreated CF is mainly composed of carbon and oxygen. After constructing a silane coating contained negative charge on the $\mathrm{CF}-\mathrm{KNH}^{+}$surface, the characteristic peaks of Si2p (109 eV) and N1s (399 eV) elements initially appear on the CF-KNH ${ }^{+}$surface. It proves that the silane coating contained negative charge is successfully constructed on the $\mathrm{CF}-\mathrm{KNH}^{+}$surface. After adsorbed GO, the content of $\mathrm{N}$ element and Si element drops sharply. To better reveal the modification process, high resolution spectra of $\mathrm{C} 1 \mathrm{~s}$ were analyzed. Compared with the untreated $\mathrm{CF}, \mathrm{CF}-\mathrm{KHN}^{+}$has two new peaks at $284.6 \mathrm{eV}$ and $284.3 \mathrm{eV}$ ascribed to the C-N and C-Si, as shown in Figure 5c. This result proves that the construction of silane coating contained negative charge is successfully constructed on the $\mathrm{CF}_{-} \mathrm{KHN}^{+}$surface. For CF-KHN ${ }^{+}-4 \mathrm{GO}$, it can be observed in the spectrum that the C-N bond decreases and the $\mathrm{C}-\mathrm{Si}$ bond disappears. Additionally, the enhancements of $\mathrm{O}-\mathrm{C}=\mathrm{O}$ contents could be attributed to the introduction of GO nanosheets.
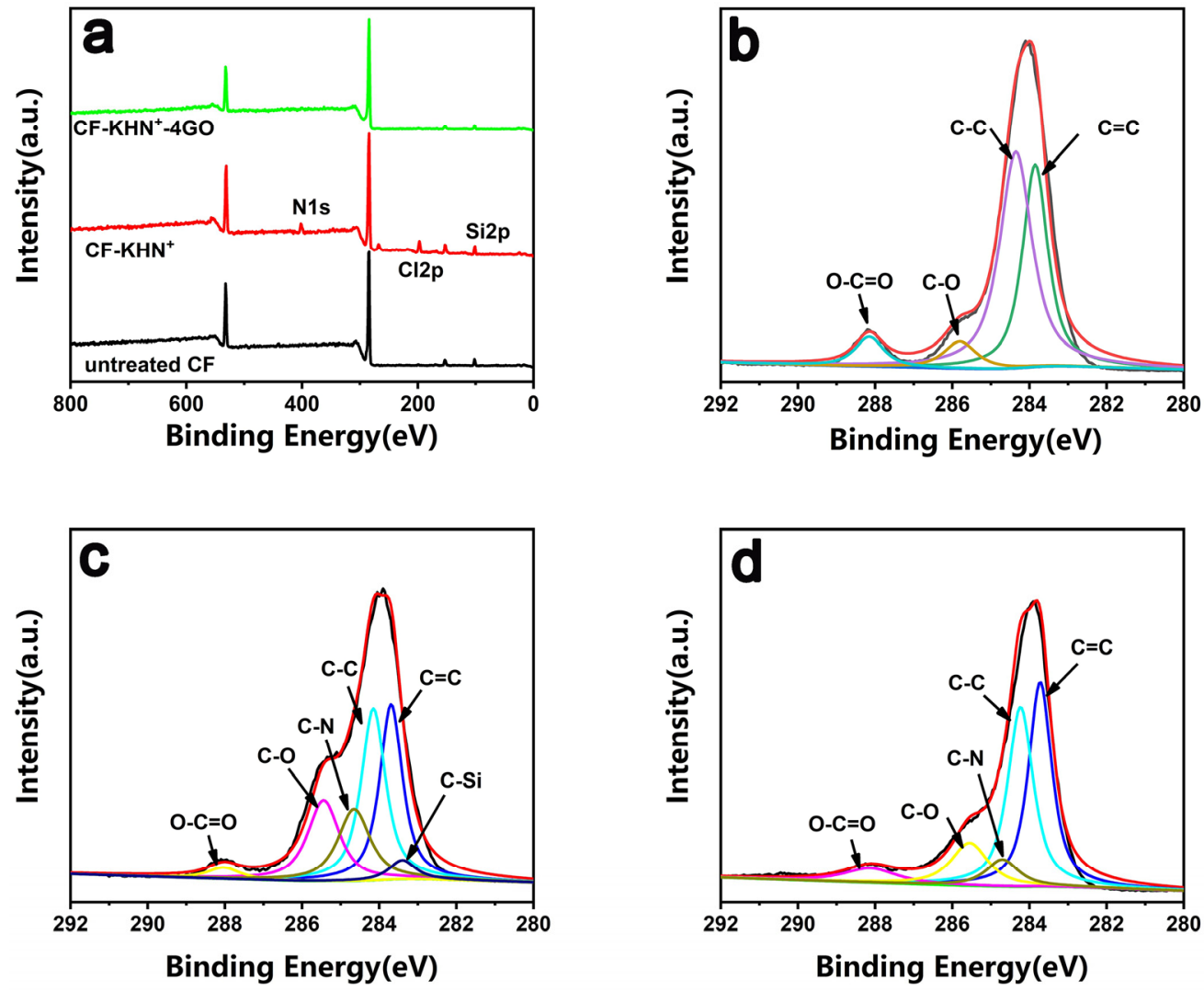

Figure 5. XPS full spectra of carbon fibers (a) and XPS curve fitting of carbon fibers. (b) Untreated CF,

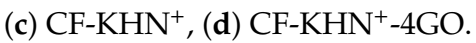




\subsection{Surface Morphology of CF}

As shown in Figure 6, SEM was used to observe the surface morphology and surface characteristics of different $\mathrm{CF}$. The surface of untreated $\mathrm{CF}$ is relatively smooth and clean (Figure 6a). Some shallow grooves left during the preparation process can be observed. These grooves were parallel arranged along with the axial direction of CF. Compared with untreated $\mathrm{CF}$, the silane coating on the surface of $\mathrm{CF}-\mathrm{KNH}^{+}$filled the grooves on the fiber surface and formed new wrinkles.
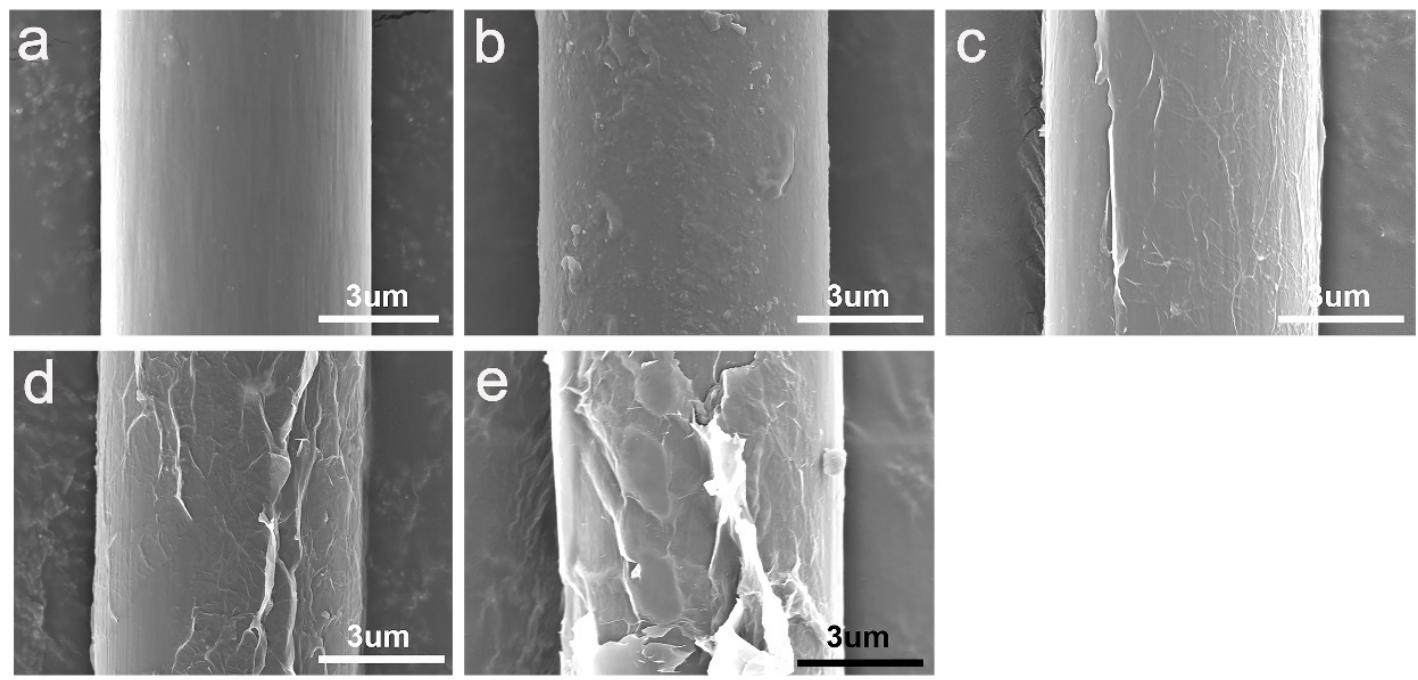

Figure 6. SEM images of carbon fibers (a) Untreated CF, (b) $\mathrm{CF}-\mathrm{KHN}^{+}$, (c) $\mathrm{CF}-\mathrm{KHN}^{+}-2 \mathrm{GO}$, (d) CF$\mathrm{KHN}^{+}-4 \mathrm{GO},(\mathbf{e}) \mathrm{CF}-\mathrm{KHN}^{+}-6 \mathrm{GO}$.

Remarkably, differences of the surface morphology can be observed after absorbing $\mathrm{GO}$, as shown in Figure 6c-e. In order to further study the influence of graphene oxide content on surface morphology, three multi-scale reinforcements $\left(\mathrm{CF}-\mathrm{KHN}^{+}-2 \mathrm{GO}, \mathrm{CF}-\right.$ $\mathrm{KHN}^{+}-4 \mathrm{GO}, \mathrm{CF}-\mathrm{KHN}{ }^{+}-6 \mathrm{GO}$ ) were prepared. $\mathrm{GO}$ is attached onto the $\mathrm{CF}-\mathrm{KHN}^{+}$surface, however, the density of GO is different. It is easy to understand that $\mathrm{CF}$ have a high GO density after being treated with high concentration of GO aqueous suspension. In Figure $6 c$, only a small amount of GO could be observed attached onto the surface of $\mathrm{CF}-\mathrm{KHN}^{+}-2 \mathrm{GO}$. The foremost reason is that the content of GO is little, which limits its adsorption onto the positively charged silane coating. As shown in Figure 6d, the entire $\mathrm{CF}-\mathrm{KHN}^{+}-4 \mathrm{GO}$ surface was homogeneously covered with GO nanosheets. However, a large number of GO nanosheets were concentrated onto the $\mathrm{CF}-\mathrm{KHN}^{+}-6 \mathrm{GO}$ surface (Figure 6e), and forming huge wrinkles and big blocks. Superfluous GO nanosheets lead to aggregation/agglomeration phenomena that can generate stress concentrations and decrease the energy dissipation capability, which result in less effective interfacial enhancement of its composite.

The surface roughness ( $\mathrm{Ra}$ ) was also quantitatively characterized by AFM. Compared with the untreated $\mathrm{CF}$, the $\mathrm{CF}-\mathrm{KHN}^{+}$surface roughness has also been increased from $13.5 \mathrm{~nm}$ (Figure 7a) to $37.1 \mathrm{~nm}$ (Figure $7 \mathrm{~b}$ ). Its noteworthiness is that the surface roughness of CF-KHN ${ }^{+}-2 \mathrm{GO}(\mathrm{Ra}=40.2 \mathrm{~nm})$ has no significant change. The main reason is that the $\mathrm{GO}$ content is too low, and the adsorption amount is small. The fiber surface roughness of CF-KHN ${ }^{+}-4 \mathrm{GO}$ increased from $40.2 \mathrm{~nm}$ to $59.8 \mathrm{~nm}$ with a large margin and the GO nanosheets were distributed uniformly in different directions. Moreover, The GO played a role of locking for enhancing the interfacial adhesion between the fiber and the matrix by inserting into the composite interface region. $\mathrm{CF}-\mathrm{KHN}^{+}-6 \mathrm{GO}$ has a larger roughness of $63.5 \mathrm{~nm}$. Nevertheless, it could be found from (Figure 6e) that a large amount of GO aggregated onto the fiber surface, which is not conducive to enhance interfacial strength between the fiber and the matrix caused by stress concentration. 

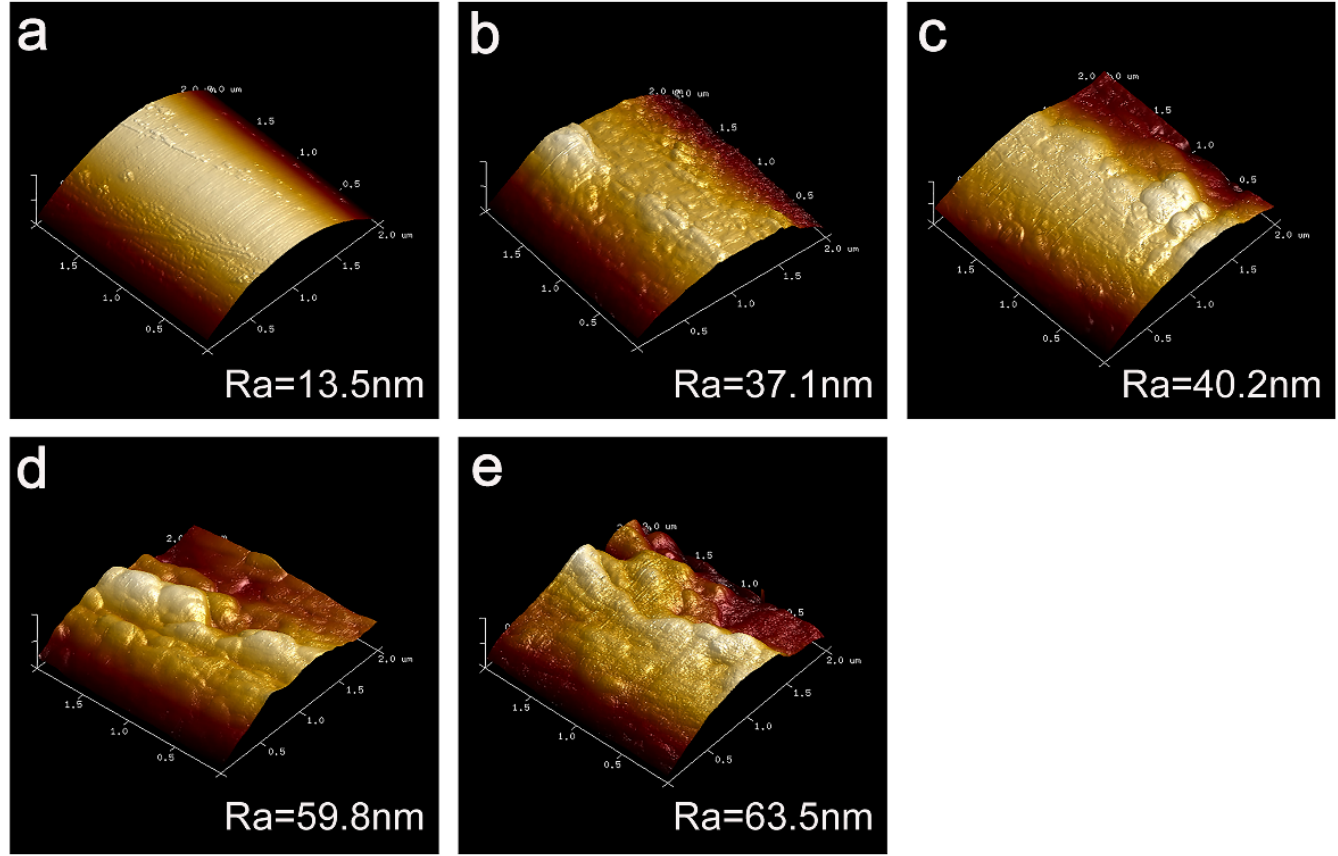

Figure 7. AFM images of carbon fibers (a) Untreated CF, (b) $\mathrm{CF}-\mathrm{KHN}^{+}$, (c) $\mathrm{CF}-\mathrm{KHN}^{+}-2 \mathrm{GO}$, (d) CF$\mathrm{KHN}^{+}-4 \mathrm{GO},(\mathbf{e}) \mathrm{CF}-\mathrm{KHN}^{+}-6 \mathrm{GO}$.

\subsection{Surface Free Energy Analysis and Wettability of CFs}

Contact angle $(\theta)$ and surface energy $(\gamma)$ of different reinforcements including dispersion component $\left(\gamma^{d}\right)$ and polar component $\left(\gamma^{p}\right)$ are summarized in Table 2. As known, chemical structure and surface morphology affect the fiber surface energy. The increase of the fiber surface energy can ameliorate the surface wettability and interfacial adhesion between $\mathrm{CF}$ and matrix [39]. The surface energy of untreated $\mathrm{CF}$ and $\mathrm{CF}-\mathrm{KNH}^{+}$is $41.16 \mathrm{mN} / \mathrm{m}$ and $45.05 \mathrm{mN} / \mathrm{m}$, respectively. The polar component of untreated CF was lower due to the less polar functional groups, the formation of the silane coating improves the polar groups on the CF surface, and increases the surface energy. After GO was introduced onto the $\mathrm{CF}$ surface by electrostatic action, the surface energy presented more distinct increasing tendency, from $41.16 \mathrm{mN} / \mathrm{m}$ to $49.46 \mathrm{mN} / \mathrm{m}$. Moreover, with the increase of GO contents, the surface energy increased evidently to $59.09 \mathrm{mN} / \mathrm{m}$ for CF-KNH ${ }^{+}-4 \mathrm{GO}$. The introduction of GO increases the number of polar groups on the fiber surface, and at the same time increases the surface roughness of the fiber. This change of surface energy is mainly caused by the increased polar component $\left(\gamma^{p}\right)$. The higher surface energy could lead to better wettability particularly, which was beneficial for the improvement of the composite's interfacial properties. The surface energy of CF- $\mathrm{KNH}^{+}-6 \mathrm{GO}$ is $57.22 \mathrm{mN} / \mathrm{m}$, which is slightly lower than that of $\mathrm{CF}-\mathrm{KNH}^{+}-4 \mathrm{GO}$. The $\gamma^{p}$ of the two reinforcements are almost equal, indicating that the content of polar groups on the surface have little difference. The $\gamma^{d}$ of CF-KNH ${ }^{+}-4 \mathrm{GO}$ is larger than CF-KNH ${ }^{+}-6 \mathrm{GO}$ because CF-KNH ${ }^{+}-4 \mathrm{GO}$ has preferable interface morphology. Hence, $\mathrm{CF}-\mathrm{KNH}^{+}-4 \mathrm{GO}$ with the highest surface energy enhances the wettability effectively and improves the interfacial strength. 
Table 2. Dynamic contact angles and surface energies of different reinforcements.

\begin{tabular}{|c|c|c|c|c|c|}
\hline & \multicolumn{2}{|c|}{ Contact Angle $\theta\left({ }^{\circ}\right)$} & \multirow{2}{*}{$\gamma^{d}(\mathrm{mN} / \mathrm{m})$} & \multirow{2}{*}{$\gamma^{p}(\mathrm{mN} / \mathrm{m})$} & \multirow{2}{*}{$\gamma(\mathrm{mN} / \mathrm{m})$} \\
\hline & Water & Diiodomethane & & & \\
\hline Untreated CF & 69.8 & 56.3 & 30.70 & 10.46 & 41.16 \\
\hline CF-KNH ${ }^{+}$ & 65.4 & 52.1 & 33.10 & 11.95 & 45.05 \\
\hline $\mathrm{CF}_{-} \mathrm{KNH}^{+}-2 \mathrm{GO}$ & 61.7 & 44.9 & 37.06 & 12.4 & 49.46 \\
\hline $\mathrm{CF}-\mathrm{KNH}^{+}-4 \mathrm{GO}$ & 50.2 & 34.7 & 42.17 & 16.92 & 59.09 \\
\hline $\mathrm{CF}^{-\mathrm{KNH}^{+}-6 \mathrm{GO}}$ & 50.6 & 35.8 & 41.66 & 16.83 & 57.22 \\
\hline
\end{tabular}

\subsection{Interfacial Property Testing of Composites}

The study of flexural properties adopting three-point bending mode could comprehensively reflect the mechanical performance of CF/PPEK composites involved tensile, compressive and shear forces form frequently met in the engineering applications. As shown in Figure 8, the flexural strength and modulus of untreated CF/PPEK composite are $1128 \mathrm{MPa}$ and $95.00 \mathrm{GPa}$, whereas flexural strength and modulus of $\mathrm{CF}-\mathrm{KNH}^{+} / \mathrm{PPEK}$ composite are $1180 \mathrm{MPa}$ and $97.5 \mathrm{GPa}$. After $\mathrm{KHN}^{+}$coating, the polar groups onto the CF surface can increase the fiber surface energy, and the wettability with PPEK have been enhanced, which is accountable for the improvement in interfacial bonding properties. The flexural strengths of CF-KNH ${ }^{+}-2 \mathrm{GO} / \mathrm{PPEK}, \mathrm{CF}-\mathrm{KNH}^{+}-4 \mathrm{GO} / \mathrm{PPEK}$, and CF-KNH ${ }^{+}$ 6GO/PPEK composites are $1248 \mathrm{MPa}, 1508 \mathrm{MPa}$ and $1362 \mathrm{MPa}$, respectively. The high flexural strength after the surface treatment is mainly owing to the increase of its interface strength. In the interface layer, the electrostatic interaction between the GO nanosheets layer and the $\mathrm{CF}$ improves the stress transfer efficiency from the matrix to the reinforcement under the action of environmental stress relieves the stress concentration caused by interface defects and increases the stress bearing capacity. The Stress-Strain curves of untreated $\mathrm{CF} / \mathrm{PPEK}$ composites and CF-KNH ${ }^{+}-4 \mathrm{GO} / \mathrm{PPEK}$ composites were presented in Figure S4. It is still noteworthy that the variation tendency of flexural modulus was the same as that of flexural strength. The flexural modulus of CF-KNH ${ }^{+}-2 \mathrm{GO} / \mathrm{PPEK}, \mathrm{CF}-\mathrm{KNH}^{+}-4 \mathrm{GO} / \mathrm{PPEK}$, and CF-KNH ${ }^{+}-6 \mathrm{GO} / \mathrm{PPEK}$ composites were $102 \mathrm{GPa}, 107 \mathrm{GPa}$ and $102 \mathrm{GPa}$, respectively. $\mathrm{CF}-\mathrm{KNH}^{+}-4 \mathrm{GO} / \mathrm{PPEK}$ exhibits the highest strengthening effect (107 GPa). The uniform distribution of GO nanosheets in the interface layer, the best mechanical interlocking and wettability between $\mathrm{CF}-\mathrm{KNH}^{+}-4 \mathrm{GO}$ and PPEK result in the strongest interface adhesion for $\mathrm{CF}-\mathrm{KNH}^{+}-4 \mathrm{GO} / \mathrm{PPEK}$ composite, which restricts the movement of PPEK molecules at the interface, and leads to the greatest flexural strength and modulus.
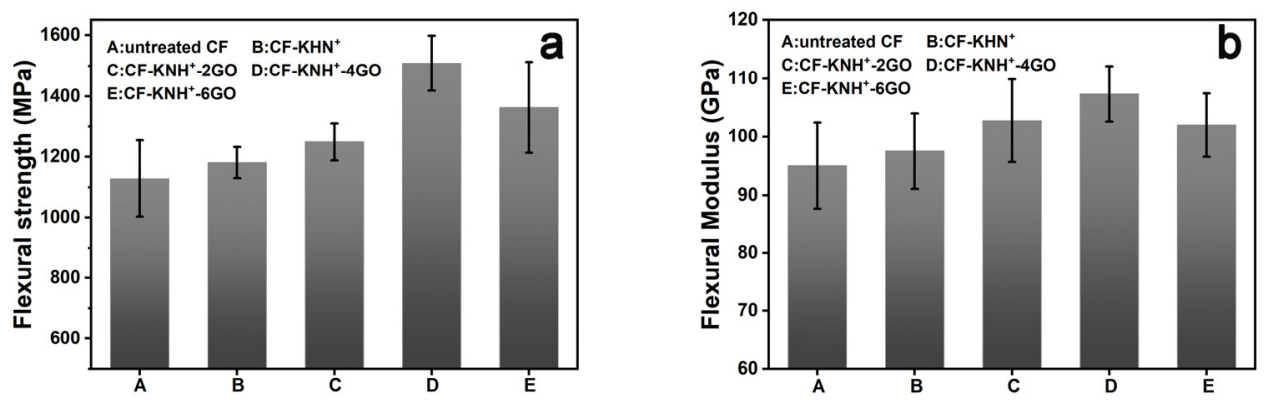

Figure 8. (a) Flexural strength of GO/CF multiscale composites and (b) Flexural Modulus of GO/CF multiscale composites.

The short beam three-point bending method was utilized to characterize the interlaminar shear strength (ILSS) of the CF/PPEK composites, as shown in Figure 9. The ILSS value of the untreated $\mathrm{CF} / \mathrm{PPEK}$ composite is $57.00 \mathrm{MPa}$. As the $\mathrm{KNH}^{+}$were coated onto CF surfaces, $\mathrm{CF}-\mathrm{KHN}^{+}$/ PPEK composite showed the higher interlaminar shear strength (59.69 MPa). The introduction of $\mathrm{KNH}^{+}$onto $\mathrm{CF}$ surfaces is beneficial to the infiltration of $\mathrm{CF}$ by the resin matrix because it can favor increasing fiber surface energy. Compared with 
$\mathrm{CF} \mathrm{KHN}^{+} / \mathrm{PPEK}$ composite, the ILSS of CF-KHN ${ }^{+}-2 \mathrm{GO} / \mathrm{PPEK}$ composite is $65.33 \mathrm{MPa}$ with $9.45 \%$ increment. The introduced $0.2 \mathrm{wt} \% \mathrm{GO}$ on fiber surface do not ameliorate ILSS efficaciously which is may due to the poor wettability as well as weak mechanical interlock between GO and PPEK. When the concentration of graphene oxide is $0.4 \mathrm{wt} \%$, $\mathrm{GO}$ is distributed on fiber surface without significant agglomeration. The interface area effectively hardening favors improve the stress transfer efficiencies. Hence, ILSS of CF$\mathrm{KHN}^{+}-4 \mathrm{GO} / \mathrm{PPEK}$ composite remarkably increases to $74.57 \mathrm{MPa}$. Relative decrease of the ILSS value of CF-KHN ${ }^{+}-6 \mathrm{GO}(70.79 \mathrm{MPa})$ was observed due to the agglomeration of $\mathrm{GO}$ in the interface region and that has been confirmed by Figure 6e. The change rule of mechanical properties is the same as SEM and AFM image analysis.

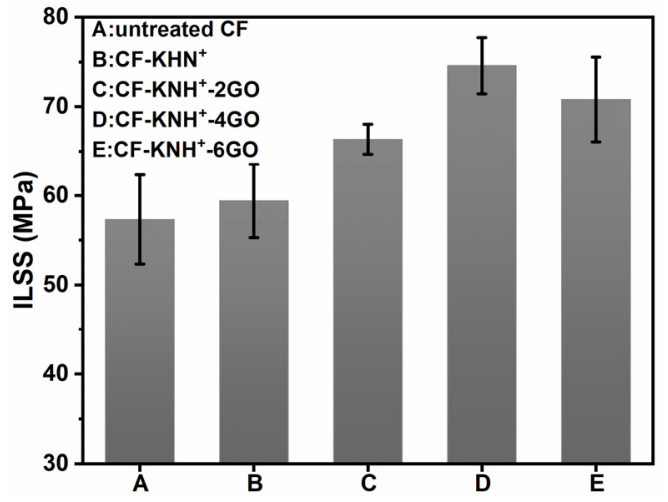

Figure 9. ILSS of GO/CF multiscale composites.

\subsection{Fractured Surface Morphology of Composites}

To determine the interface enhancement mechanism for CF-KHN ${ }^{+}-4 \mathrm{GO} / \mathrm{PPEK}$ composite, the cross-sectional morphologies of the untreated $\mathrm{CF}$ composite and $\mathrm{CF}-\mathrm{KHN}^{+}-4 \mathrm{GO}$ composite were verified by SEM, as shown in Figure 10, for untreated CF composite (Figure 10a), a lot of CF were pulled out from the PPEK, and some holes remained in the PPEK matrix as a result of the weak interface combination between the untreated CF and

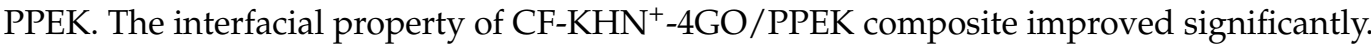
The fiber debonding, holes, and pulled-out fibers on the CF-KHN ${ }^{+}-4 \mathrm{GO} / \mathrm{PPEK}$ composite fractured surface have not been found.
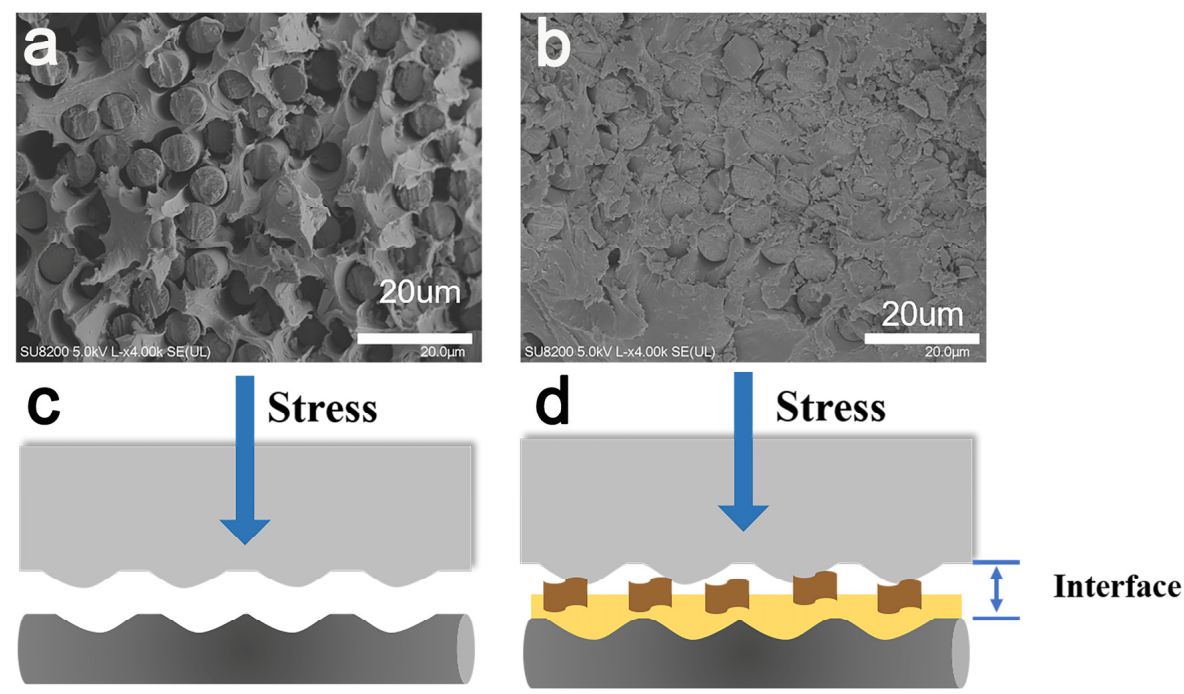

Figure 10. SEM morphologies of the flexural fracture surface of (a) Untreated CF/PPEK; (b) CF$\mathrm{KHN}^{+}-4 \mathrm{GO} / \mathrm{PPEK}$; Proposed failure mechanism of composites: (c) Untreated CF/PPEK, (d) CF$\mathrm{KHN}^{+}-4 \mathrm{GO} / \mathrm{PPEK}$. 
The microscopic fracture mechanism was seen to be interfacial adhesion failure and the schematic diagrams were displayed in Figure 10c,d. The untreated CF has low surface roughness $(\mathrm{Ra}=13.5 \mathrm{~nm})$ and low surface energy $(41.16 \mathrm{mN} / \mathrm{m})$ (Figure 7a and Table 2). PPEK with high viscosity is difficult to infiltrate completely untreated CF bundles, which would cause gaps, holes and other defects between the fibers and the PPEK matrix. Under stress, cracks propagate along the interface and gradually develop leading to interface failure. When the carbon fiber was modified by GO nanosheets, the mechanical interlock between $\mathrm{CF}-\mathrm{KHN}^{+}-4 \mathrm{GO}$ and PPEK matrix is strengthened by the increase of the fiber surface roughness. Owing to the existence of GO nanosheets, the crack is blunted and turned to prevent the crack from propagating. With the increase of external force, the PPEK resin in the composite material yields and even the carbon fiber breaks.

Figure 11 shows the SEM morphologies of the ILSS fracture of different composite samples. For untreated CF composite (Figure 11a), a large number of bare CF are exposed, a typical feature of interface failure. Many voids and cracks are observed in untreated CF/PPEK. Fibers with a smooth surface were debonded from the PPEK matrix, suggested that the adhesive failure was initiated along fiber surface due to the poor interfacial bonding. However, for the CF-KHN ${ }^{+}-4 \mathrm{GO} / \mathrm{PPEK}$ composite (Figure 11b), PPEK matrix layer covers on fibers, and some fragmented resins were adsorbed on the fiber surface. The CF-KHN ${ }^{+}-4 \mathrm{GO} / \mathrm{PPEK}$ composite showed typical matrix failure characteristics under shear force $[40,41]$, the fracture occurred at the matrix because the interfacial strength between the fiber and the matrix was improved by absorbing GO. The fracture model was changed from pure fibers broke to the combination failures of fibers broke, interface and delamination $[42,43]$. Therefore, GO nanosheets significantly improve the interface bonding between the fibers and the matrix by increasing surface roughness and polarity of CF.
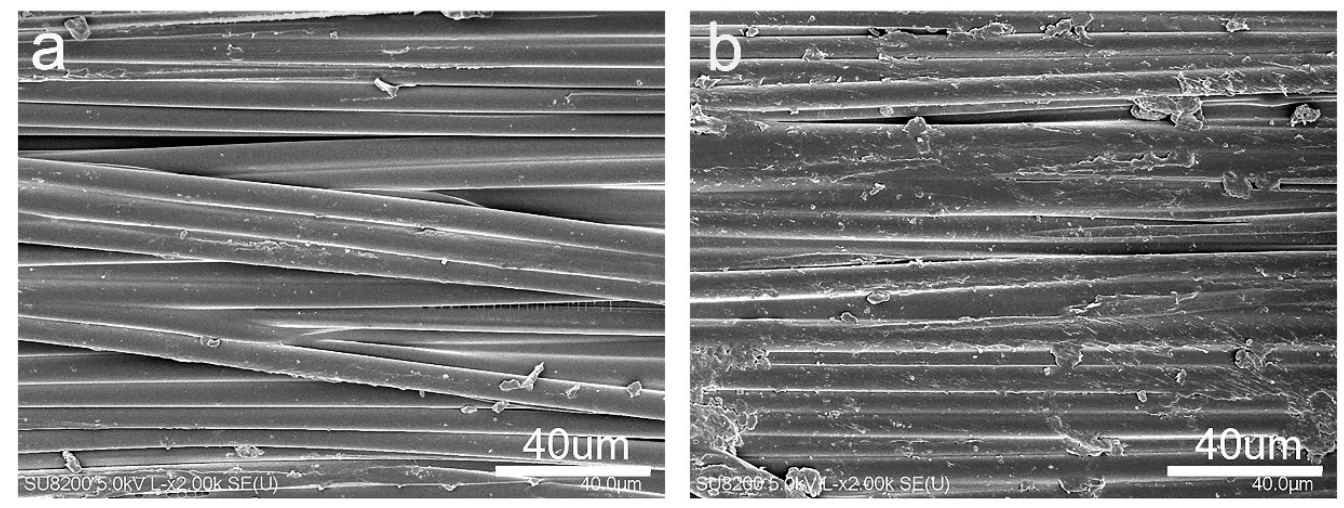

Figure 11. SEM morphologies of ILSS fracture surface of composite: (a) Untreated CF and (b) CF$\mathrm{KHN}^{+}-4 \mathrm{GO}$.

Dynamic mechanical analysis (DMA) has been generally applied to characterize the interfacial adhesion of assorted polymeric systems. The temperature dependence of the storage modulus for different composites are shown in Figure 12a. The initial modulus

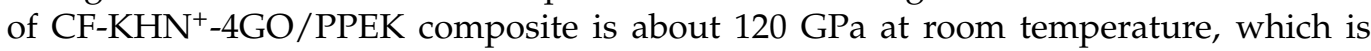
surmounted that of untreated CF/PPEK composite (90 GPa). The silane/GO hybrid rigid interface layer increases the thickness of the interface phase and the volume content of the reinforcement in the composite material. This result is in good agreement with that of flexural modulus. 

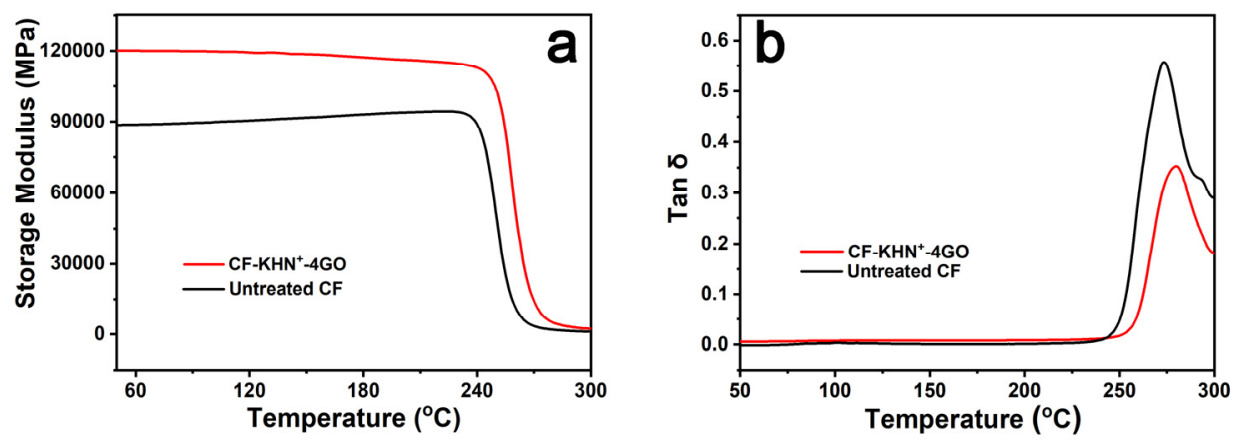

Figure 12. Temperature dependence of untreated CF/PPEK and CF/GO/PPEK composites: (a) storage modulus, and (b) loss tangent delta.

It is well-known that $T_{g}$ can be defined as the max value of $\tan \delta$ with a low frequency. Figure $12 \mathrm{~b}$ shows that the untreated CF/PPEK composite has a $T_{g}$ of $277^{\circ} \mathrm{C}$, and the $T_{g}$ of $\mathrm{CF}-\mathrm{KNH}^{+}-4 \mathrm{GO} / \mathrm{PPEK}$ composite is approximately $9{ }^{\circ} \mathrm{C}$ higher than its counterpart. The silane/GO hybrid rigid interface layer restricts the movement of the matrix resin near the interfacial phase. Additionally, the loss factor $\tan \delta$ reflects the balance of elasticity and viscosity in the composite. With the loss factor $\tan \delta$ increasing, the viscosity of the composite increases and the elasticity decreases. The weaker the interface bonding of the composite, the larger the loss factor $\tan \delta$ [30]. The interface bonding of untreated CF/PPEK composites is weak, and the loss factor $\tan \delta$ peak value is 0.57. After silane/GO modification, the interface bonding between $\mathrm{CF}-\mathrm{KNH}^{+}-4 \mathrm{GO}$ and PPEK enhanced slightly, the loss factor tan $\delta$ peak value of $\mathrm{CF}-\mathrm{KNH}^{+}-4 \mathrm{GO} / \mathrm{PPEK}$ composite dropped to 0.36 , indicating that it has good interfacial property.

\section{Conclusions}

In this study, the silane/GO hybrid interface layer were constructed to enhance the interface adhesion of CF/PPEK. The results of FTIR, Raman, and XPS affirmed the successful preparation of $\mathrm{CF}-\mathrm{KNH}^{+}-4 \mathrm{GO}$ reinforcement. The SEM and AFM results manifest that the roughness increased obviously through electrostatic adsorbing GO. The surface energy of CF is also significantly increased with the addition of GO. The optimal GO content was $0.4 \mathrm{wt} \%$, with ILSS of $74.57 \mathrm{MPa}$ and flexural strength of $1508 \mathrm{MPa}$. Based on the mechanical properties investigation, the silane/GO hybrid interface layer improves the interfacial bonding strength of composite. The content of graphene oxide affects the bonding strength between fiber and resin. $\mathrm{CF}-\mathrm{KHN}^{+}-4 \mathrm{GO}$ exhibits the best interface enhancement effect, with ILSS of $74.57 \mathrm{MPa}$ and flexural strength of $1508 \mathrm{MPa}$. The reinforcing mechanisms were also elaborated that the GO sheets play the anchoring effects in interfacial area. Moreover, this method can be conveniently operated and would have great potential for using as multi-scale reinforcements in high-performance composites.

Supplementary Materials: The following are available online at https:/ /www.mdpi.com/article/ 10.3390/ma15010206/s1, Figure S1: Schematic diagram of interlaminar shear experiment, Figure S2: Schematic diagram of flexural experiment, Figure S3: (a) TGA Spectra of PPEK and CF-KHN+4GO/PPEK; (b) DSC Spectra of PPEK and CF-KHN+-4GO/PPEK.

Author Contributions: Conceptualization, S.C. and N.L.; methodology, N.L.; software, Y.P.; validation, B.W., H.H. and S.C.; formal analysis, N.L.; investigation, S.C.; resources, N.L.; data curation, C.L.; writing — original draft preparation, S.C.; writing—review and editing, N.L. AND Y.P.; visualization, F.H.; supervision, Y.C.; project administration, X.J.; funding acquisition, X.J. All authors have read and agreed to the published version of the manuscript.

Funding: This research was funded by the State Key Laboratory for Modification of Chemical Fibers and Polymer Materials, Donghua University (KF2002), the National Science Foundation of China (U1837205; 91860204), the National Natural Science Foundation of China (NO. 91860204), the Fundamental Research Funds for the Central Universities (DUT20LAB305).and the National Key 
Research and Development Program of China (2020YFB0311600; 2017YFB0307600), the Fundamental Research Funds for the Central Universities (DUT19RC(3)037).

Institutional Review Board Statement: Not applicable.

Informed Consent Statement: Not applicable.

Data Availability Statement: Data sharing is not applicable for this article.

Acknowledgments: The authors gratefully acknowledge the supports from the State Key Laboratory for Modification of Chemical Fibers and Polymer Materials, Donghua University (KF2002), the National Science Foundation of China (U1837205; 91860204), the National Natural Science Foundation of China (NO. 91860204), the Fundamental Research Funds for the Central Universities (DUT20LAB305).and the National Key Research and Development Program of China (2020YFB0311600; 2017YFB0307600), the Fundamental Research Funds for the Central Universities (DUT19RC(3)037).

Conflicts of Interest: The authors declare that they have no conflict of interest.

\section{References}

1. Li, N.; Yang, X.; Bao, F.; Pan, Y.; Wang, C.; Chen, B.; Zong, L.; Liu, C.; Wang, J.; Jian, X. Improved Mechanical Properties of Copoly(Phthalazinone Ether Sulphone)s Composites Reinforced by Multiscale Carbon Fibre/Graphene Oxide Reinforcements: A Step Closer to Industrial Production. Polymers 2019, 11, 237. [CrossRef] [PubMed]

2. Li, N.; Wu, Z.; Yang, X.; Wang, C.; Zong, L.; Pan, Y.; Wang, J.; Jian, X. One-pot strategy for covalent construction of POSS-modified silane layer on carbon fiber to enhance interfacial properties and anti-hydrothermal aging behaviors of PPBES composites. $J$. Mater. Sci. 2018, 53, 16303-16317. [CrossRef]

3. Dong, J.; Ma, X.; Xiao, L.; Ao, Y. Carbon fiber composite of phenolic resin matrix: Study on preparation and frictional wear performance. New Chem. Mater. 2017, 45, 116-118.

4. Zeng, L.; Liu, X.; Chen, X.; Soutis, C. Pi-Pi interaction between carbon fibre and epoxy resin for interface improvement in composites. Compos. Part B Eng. 2021, 220, 108983. [CrossRef]

5. Thomas, A.J.; Kim, J.J.; Tallman, T.N.; Bakis, C.E. Damage detection in self-sensing composite tubes via electrical impedance tomography. Compos. Part B Eng. 2019, 177, 107276. [CrossRef]

6. Liu, Y.-T.; Song, H.-Y.; Yao, T.-T.; Zhang, W.-S.; Zhu, H.; Wu, G.-P. Effects of carbon nanotube length on interfacial properties of carbon fiber reinforced thermoplastic composites. J. Mater. Sci. 2020, 55, 15467-15480. [CrossRef]

7. Kwon, Y.J.; Kim, Y.; Jeon, H.; Cho, S.; Lee, W.; Lee, J.U. Graphene/carbon nanotube hybrid as a multi-functional interfacial reinforcement for carbon fiber-reinforced composites. Compos. Part B Eng. 2017, 122, 23-30. [CrossRef]

8. Zhang, T.; Cheng, Q.; Xu, Z.; Jiang, B.; Wang, C.; Huang, Y. Improved interfacial property of carbon fiber composites with carbon nanotube and graphene oxide as multi-scale synergetic reinforcements. Compos. Part A Appl. Sci. Manuf. 2019, 125, 105573. [CrossRef]

9. Xiong, L.; Zhan, F.; Liang, H.; Chen, L.; Lan, D. Chemical grafting of nano- $\mathrm{TiO}_{2}$ onto carbon fiber via thiol-ene click chemistry and its effect on the interfacial and mechanical properties of carbon fiber/epoxy composites. J. Mater. Sci. 2018, 53, $2594-2603$. [CrossRef]

10. Wang, F.; Cai, X. Improvement of mechanical properties and thermal conductivity of carbon fiber laminated composites through depositing graphene nanoplatelets on fibers. J. Mater. Sci. 2019, 54, 3847-3862. [CrossRef]

11. Yan, F.; Liu, L.; Li, M.; Zhang, M.; Xiao, L.; Ao, Y. Preparation of carbon nanotube/copper/carbon fiber hierarchical composites by electrophoretic deposition for enhanced thermal conductivity and interfacial properties. J. Mater. Sci. 2018, 53, 8108-8119. [CrossRef]

12. Lee, E.-S.; Lee, C.-H.; Chun, Y.-S.; Han, C.-J.; Lim, D.-S. Effect of hydrogen plasma-mediated surface modification of carbon fibers on the mechanical properties of carbon-fiber-reinforced polyetherimide composites. Compos. Part B Eng. 2017, 116, 451-458. [CrossRef]

13. Yim, Y.-J.; Bae, K.-M.; Park, S.-J. Influence of Oxyfluorination on Geometrical Pull-Out Behavior of Carbon-Fiber-Reinforced Epoxy Matrix Composites. Macromol. Res. 2018, 26, 794-799. [CrossRef]

14. Liu, L.; Yan, F.; Li, M.; Zhang, M.; Xiao, L.; Shang, L.; Ao, Y. A novel thermoplastic sizing containing graphene oxide functionalized with structural analogs of matrix for improving interfacial adhesion of CF/PES composites. Compos. Part A Appl. Sci. Manuf. 2018, 114, 418-428. [CrossRef]

15. Wang, X.; Li, C.; Chi, Y.; Piao, M.; Chu, J.; Zhang, H.; Li, Z.; Wei, W. Effect of Graphene Nanowall Size on the Interfacial Strength of Carbon Fiber Reinforced Composites. Nanomaterials 2018, 8, 414. [CrossRef]

16. Hu, J.Q.; Li, F.; Wang, B.; Zhang, H.Q.; Ji, C.M.; Wang, S.X.; Zhou, Z.G. A two-step combination strategy for significantly enhancing the interfacial adhesion of CF/PPS composites: The liquid-phase oxidation followed by grafting of silane coupling agent. Compos. Part B Eng. 2020, 191, 12. [CrossRef] 
17. Yao, X.M.; Gao, X.Y.; Jiang, J.J.; Xu, C.M.; Deng, C.; Wang, J.B. Comparison of carbon nanotubes and graphene oxide coated carbon fiber for improving the interfacial properties of carbon fiber/epoxy composites. Compos. Part B Eng. 2018, 132, 170-177. [CrossRef]

18. Wang, C.; Zhao, M.; Li, J.; Yu, J.; Sun, S.; Ge, S.; Guo, X.; Xie, F.; Jiang, B.; Wujcik, E.K.; et al. Silver nanoparticles/graphene oxide decorated carbon fiber synergistic reinforcement in epoxy-based composites. Polymer 2017, 131, 263-271. [CrossRef]

19. Kinloch, I.A.; Suhr, J.; Lou, J.; Young, R.J.; Ajayan, P.M. Composites with carbon nanotubes and graphene: An outlook. Science 2018, 362, 547-553. [CrossRef]

20. He, M.; Xu, P.; Zhang, Y.; Liu, K.; Yang, X. Phthalocyanine nanowires@GO/carbon fiber composites with enhanced interfacial properties and electromagnetic interference shielding performance. Chem. Eng. J. 2020, 388, 124255. [CrossRef]

21. Wang, C.; Li, J.; Yu, J.; Sun, S.; Li, X.; Xie, F.; Jiang, B.; Wu, G.; Yu, F.; Huang, Y. Grafting of size-controlled graphene oxide sheets onto carbon fiber for reinforcement of carbon fiber/epoxy composite interfacial strength. Compos. Part A Appl. Sci. Manuf. 2017, 101, 511-520. [CrossRef]

22. Liu, L.; Yan, F.; Li, M.; Zhang, M.J.; Xiao, L.H.; Shang, L.; Ao, Y.H. Improving interfacial properties of hierarchical reinforcement carbon fibers modified by graphene oxide with different bonding types. Compos. Part A Appl. Sci. Manuf. 2018, 107, 616-625. [CrossRef]

23. Zheng, H.; Li, Q.; Yu, C.; Zhu, X.; Guo, P.; Mu, Y.; Ma, L. The direct architecture of carbon fiber-carbon nanofiber hierarchical reinforcements for superior interfacial properties of CF/epoxy composites. Polym. Adv. Technol. 2019, 30, 620-630. [CrossRef]

24. Yuan, C.; Li, D.; Yuan, X.; Liu, L.; Huang, Y. Preparation of semi-aliphatic polyimide for organic-solvent-free sizing agent in CF/PEEK composites. Compos. Sci. Technol. 2021, 201, 108490. [CrossRef]

25. Yuan, X.; Jiang, J.; Wei, H.; Yuan, C.; Wang, M.; Zhang, D.; Liu, L.; Huang, Y.; Gao, G.-L.; Jiang, Z. PAI/MXene sizing-based dual functional coating for carbon fiber/PEEK composite. Compos. Sci. Technol. 2021, 201, 108496. [CrossRef]

26. Jiao, W.; Liu, W.; Yang, F.; Jiang, L.; Jiao, W.; Wang, R. Improving the interfacial property of carbon fiber/vinyl ester resin composite by grafting modification of sizing agent on carbon fiber surface. J. Mater. Sci. 2017, 52, 13812-13828. [CrossRef]

27. Zhu, P.; Shi, J.; Bao, L. Effect of polyetherimide nanoparticle coating on the interfacial shear strength between carbon fiber and thermoplastic resins. Appl. Surf. Sci. 2020, 509, 145395. [CrossRef]

28. Zhang, W.; Deng, X.; Sui, G.; Yang, X. Improving interfacial and mechanical properties of carbon nanotube-sized carbon fiber/epoxy composites. Carbon 2019, 145, 629-639. [CrossRef]

29. Wang, T.; Jiao, Y.S.; Mi, Z.M.; Li, J.T.; Wang, D.R.N.; Zhao, X.G.; Zhou, H.W.; Chen, C.H. PEEK composites with polyimide sizing SCF as reinforcement: Preparation, characterization, and mechanical properties. High. Perform. Polym. 2020, 32, 383-393. [CrossRef]

30. Wen, Z.; Xu, C.; Qian, X.; Zhang, Y.; Wang, X.; Song, S.; Dai, M.; Zhang, C. A two-step carbon fiber surface treatment and its effect on the interfacial properties of $\mathrm{CF} / \mathrm{EP}$ composites: The electrochemical oxidation followed by grafting of silane coupling agent. Appl. Surf. Sci. 2019, 486, 546-554. [CrossRef]

31. Moreno-Castilla, C. Adsorption of organic molecules from aqueous solutions on carbon materials. Carbon 2004, 42, 83-94. [CrossRef]

32. Zhu, S.; He, S.; Gao, J.; Elwathig, A.M.H.; Ge, D.; Liu, Q.; Guo, W.; Yu, M. Polyetheretherketone Matrix Composites Based on Graphene Oxide Modified Activated Carbon Fibers. Polym. Mater. Sci. Eng. 2019, 35, 130.

33. Chang, Q.; Zhao, H.; He, R. The mechanical properties of plasma-treated carbon fiber reinforced PA6 composites with CNT. Surf. Interface Anal. 2017, 49, 1244-1248. [CrossRef]

34. Wu, G.; Ma, L.; Jiang, H.; Liu, L.; Huang, Y. Improving the interfacial strength of silicone resin composites by chemically grafting silica nanoparticles on carbon fiber. Compos. Sci. Technol. 2017, 153, 160-167. [CrossRef]

35. Sun, J.; Zhao, F.; Yao, Y.; Jin, Z.; Liu, X.; Huang, Y. High efficient and continuous surface modification of carbon fibers with improved tensile strength and interfacial adhesion. Appl. Surf. Sci. 2017, 412, 424-435. [CrossRef]

36. $\mathrm{Wu}, \mathrm{N}$.; She, X.; Yang, D.; Wu, X.; Su, F.; Chen, Y. Synthesis of network reduced graphene oxide in polystyrene matrix by a two-step reduction method for superior conductivity of the composite. J. Mater. Chem. 2012, 22, 17254-17261. [CrossRef]

37. Qian, X.; Zhong, J.; Zhi, J.; Heng, F.; Wang, X.; Zhang, Y.; Song, S. Electrochemical surface modification of polyacrylonitrile-based ultrahigh modulus carbon fibers and its effect on the interfacial properties of UHMCF/EP composites. Compos. Part B Eng. 2019, 164, 476-484. [CrossRef]

38. Yamauchi, S.; Kurimoto, Y. Raman spectroscopic study on pyrolyzed wood and bark of Japanese cedar: Temperature dependence of Raman parameters. J. Wood Sci. 2003, 49, 235-240. [CrossRef]

39. Zhao, M.; Meng, L.; Ma, L.; Wu, G.; Wang, Y.; Xie, F.; Huang, Y. Interfacially reinforced carbon fiber/epoxy composites by grafting melamine onto carbon fibers in supercritical methanol. RSC Adv. 2016, 6, 29654-29662. [CrossRef]

40. Ageorges, C.; Friedrich, K.; Ye, L. Experiments to relate carbon-fibre surface treatments to composite mechanical properties. Compos. Sci. Technol. 1999, 59, 2101-2113. [CrossRef]

41. Hernandez, T.P.A.; Mills, A.R.; Nezhad, H.Y. Shear driven deformation and damage mechanisms in High-performance carbon Fibre-reinforced thermoplastic and toughened thermoset composites subjected to high strain loading. Compos. Struct. 2021, 261, 113289. [CrossRef] 
42. Li, N.; Zong, L.; Wu, Z.; Wang, X.; Bao, F.; Wang, J.; Jian, X. Compatibilization effect of aminated poly(phthalazinone ether ketone)s in carbon fiber-reinforced copoly(phthalazinone ether sulfone)s composites. Polym. Compos. 2018, 39, 4139-4147. [CrossRef]

43. Chou, C.T.; Gaur, U.; Miller, B. Fracture mechanisms during fiber pull-out for carbon-fiber-reinforced thermosetting composites. Compos. Sci. Technol. 1993, 48, 307-316. [CrossRef] 